\title{
Problems and possibilities of distance education use among students, who study according to "Physical culture" profile
}

\author{
Mariia Rusinova*, Kristina Porseva, Inna Puchkareva \\ Ural State Pedagogical University, 620017, Yekaterinburg, Russia
}

\begin{abstract}
Digital technologies introduction into the sphere of education is an urgent problem. Nowadays specialists both underline positive and negative sides of transfer into digital sphere. However, in terms of coronovirus infection pandemic most part of educational establishments was forced to use distance education. The aim of the present research work was to reveal the attitude of students to distant form of education, the difficulties and possibilities of this direction development. As the research methods we used survey, statistical instruments of data handling and Google Forms. On the basis of the survey we revealed the attitude of students to distance education in general and to lectures and practical lessons, including the disciplines of sports orientation. During the survey we defined the main reasons. They prevent effective educational process realization using distant technologies. We defined the problems, possibilities and conditions for an effective use of distant forms of education.
\end{abstract}

\section{Introduction}

Modern system of higher education development is characterized by increasing volume of information and different technologies inclusion, especially communicative, virtual and information technologies. Education digitization is one of the priority directions of the Russian Federation state policy [1]. However, transfer to digital environment demands the existing system of education reformation, innovative methods of education use. They are based on internet-video technologies, modern multimedia interactive technologies use. They provide effectiveness of higher education system realization [2]. Mainly the claimed demands correspond with distant form of education. Distance education is understood as a form of education, "when the subjects of educational activity are divided not only in space, but also in time and realize information transfer and perception by means of virtual environment, conditioned by the strategy of teaching and studying, on the basis of special system of educational process organization, special methodologies of educational manuals creation, using electronic and internet-communicative technologies" [3].

Scientists have different opinions concerning digital technologies use, including distance education. On the one hand it is mentioned that digital technologies use provides multiple increase of mental capabilities and brain activity and plasticity. However, on the other hand it is mentioned that digital technologies use has a negative influence on thinking of modern people.

\footnotetext{
*Corresponding author: mar1883@yandex.ru
} 
For example, the skills of thorough reading disappear and it influences information perception and handling [4].

The scientists mention that distance education increases the effectiveness of electronic education in general, provides availability of education, making it possible in any point of the planet. There Internet is available and helps students independently define the tempo of studying [5]. However, distance education restricts feedback with a teacher, demands additional reconsideration of educational material and its adaptation to the peculiarities of distant form. Distant courses creation is a difficult process for a teacher. It demands good knowledge of modern technologies and the corresponding software programs. Students should have not only the skills of studying in distant regimen, but also a high level of self-discipline. Thus, the preparation to distance education is a difficult and a long-term process.

Literature sources analysis (concerning the attitude of students to distant technologies of teaching use), including online-courses, showed that in $201643 \%$ of students had a positive attitude to the idea of replacing subjects of general disciplines by online-courses and $34 \%$ of students agreed to replace the disciplines of special subjects by online-courses [6].

The attitude of students to distance education, the speed of adaptation to this form depends on many factors. The research works, held during the period of pandemic, helped to reveal that the readiness for distance education is conditioned by the quality of the educational resources content, emotional atmosphere, the ability to realize self-control and motivation to realize educational process in general.

The research works held at Northern Frontier University of Saudi Arabia showed that digital educational content, used during education, not always provides progress improvement. Very often students lack the skills of information structuring and systematization, information summing up [7]. It is also mentioned that not all students can independently define their educational needs. An obligatory condition for electronic education effectiveness should become preliminary diagnostics of students' expectations and their readiness for such educational process revelation $[8,9,10]$.

Despite the existing disadvantages, in 2020 in terms of coronovirus infection pandemic COVD-19, most part of the world educational system was forced to use distant form of education. Such changes became coercive measure for most part of educational establishments and not all establishments were ready for it. Transfer to distance education happened within a short time period, without the corresponding preparation, both for teachers and students. At the same time some specialties, because of the studied subjects specificity, faced considerable difficulties of educational material adaptation to a new format. One of such directions of training became "Pedagogical education. "Physical culture" profile". The difficulties were during sports disciplines transfer into distant format (such as "Track and field and the methodology of its teaching", "Sports games" and others).

\section{Materials and Methods}

We carried out an empiric research work in order to reveal the attitude of students to distance education, to estimate the existing difficulties and define the possibilities of this direction development. The research work was held in three stages: during the first stage we analyzed native and foreign sources concerning this problem, defined the aim and objectives of the research. Methodological base of the research formed the research works in the sphere of information- communicative technologies (A.A. Andreev, M.Yu. Bukharkina, E.S. Polat and others), theoretical basis of modern teaching technologies (G.K. Selevko, V.P. Bespalko, T.Yu. Davydov and others). During the second stage in Google Forms we created and held out a survey "The attitude of students to use distant technologies of education in terms of COVID-19 epidemic". Students of the $1^{\text {st }}-4^{\text {th }}$ courses of full-time course study, who chose the specialty "Physical culture education" took part in the survey. In general 70 people took part in the 
research. The respondents were offered to answer the questions of three groups: the first group of questions helped to estimate the attitude of students to distance education in general, reveal the difficulties. They appeared during the lessons. The students were offered to answer the questions concerning the difficulties of material perception, psychological difficulties, technical problems they had. They were offered to express their opinion concerning possibilities of distance education development and the conditions of its effective use. The second group of questions was for the effectiveness estimation and difficulties revelation in students during lectures organization. The third group of questions helped to estimate the effectiveness of practical lessons from the point of view of students. We also analyzed their requests and remarks. Students were offered to estimate material presentation, the level of the load, control over the material mastering. During the third stage of the research we handled the received results, made conclusions.

\section{Results and Discussion}

During the held survey in order to reveal the attitude of students to distance education we received the following results: answering the question about technical difficulties during educational process 37 people mentioned they had the difficulties. In general the problems were connected with unsteady Internet connection or its absence, not powerful PC, difficult interface of the platform for distance education, the absence of necessary equipment (webcam, speakers and etc.). At the same time, 33 respondents said that they didn't have any technical difficulties. Speaking about psychological difficulties during the process of education, the most widespread reason, which causes these difficulties, became the inability to focus attention at home. It can be explained by the fact that at home there are a lot of distracting factors, including such overwhelming circumstances, as the absence of isolated from other family members personal place. Also 13 respondents answered that they had psychological difficulties answering before the camera. It is explained by the absence of experience and practice of such kind of lessons.

Educational material perception estimation showed that $40 \%$ of respondents had constant difficulties in educational material perception and $40 \%$ of respondents had these difficulties at regular intervals.

The effectiveness of lectures and practical lessons organization we estimated according to 3 point scale. Lectures held remotely got the following mark Xav $=1,7$ points. Practical lessons got Xav $=1,6$ points. Thus, students subjectively estimated this form of education organization sufficiently low. It is obvious that insufficient degree of educational material adaptation, the absence of teachers' readiness and students to realize educational process in this form is a significant reason for a low level of distance education at this stage. Also students were asked the following question: "What difficulties did you face during practical lessons of sports disciplines on online platform?". $42,9 \%$ of respondents answered that it was impossible to control correct technique of exercises fulfillment, $41,4 \%$ of respondents answered that home there were no sufficient space for practical lessons, 34,3\% of respondents said that relatives stood in the way of effective practical lessons, the same amount of respondents mentioned the lack of equipment, some respondents said that lessons in such conditions increased the probability to get injuries. The main reason for being unsatisfied with distant practical lessons was insufficient material-technical base. It included all mentioned above aspects.

Then students estimated the influence of distant technologies on the level of respondents' information and communicative competence. $33 \%$ of the respondents mentioned that distance education broadened their skills of work with information technologies, $23 \%$ of respondents mentioned that they mastered new forms of communication. $30 \%$ of respondents think that distant form didn't give them new information and was completely not effective. Then the respondents answered the question: "In what conditions is it possible to use effectively the 
platforms of distance education?" Most respondents think that distant technologies use is possible only as a last resort, for example, during the same epidemic situation (fig.1).

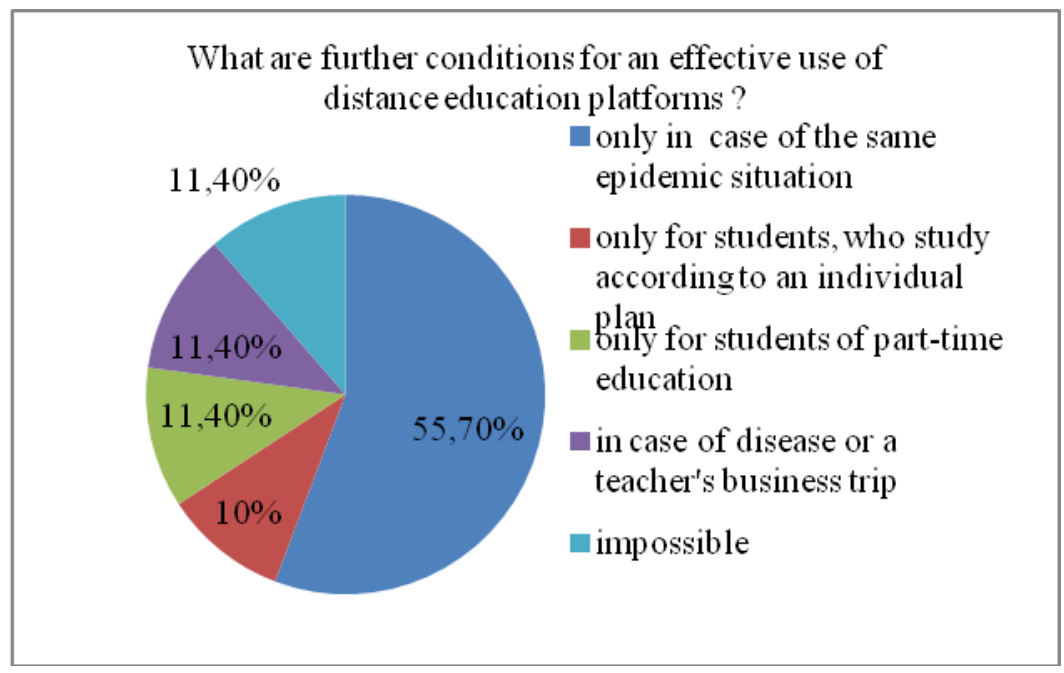

Fig.1. Answering the question: "What are further conditions for an effective use of distance education platforms?"

The respondents also mentioned that in terms of distant form the level of motivation for studying increased by $11,4 \%$, didn't change among $40 \%$ and decreased among $48,6 \%$ of the respondents. In general $10 \%$ of respondents are satisfied with distance education; $37,1 \%$ of respondents are rather satisfied, than not satisfied; $28,6 \%$ of respondents are not satisfied; $24,3 \%$ of respondents are rather not satisfied, that satisfied.

On the basis of respondents' answers analysis we defined two groups of reasons. They prevent effective use of distance education: the first group is objective reasons. Technicalconnected with the absence of necessary equipment among students and a low speed of Internet connection in some regions. Didactical- conditioned by the specificity of educational profile "Physical culture". Some disciplines can be taught online without necessary equipment or a lot of space. This program material adaptation is a long-term process. It is necessary to create differentiated tasks. They take into account different conditions and situations.

Subjective reasons are based on different mental mindsets, stereotypes, habits. They very often prevent new material mastering. These reasons can include the difficulties with selfdiscipline of students, difficulties with the work before the camera, inability to focus. Home conditions, the absence of a teacher's control during the lesson very often provide less responsible attitude to education. Distance education using different platforms, messengers and social nets changes the form of communication between a student and a teacher. Being deprived of academic character and the definite equipment (class, blackboard, rostrum) distance lesson is not always perceived by students as something serious.

\section{Conclusions}

Education digitization continues to develop very quickly. Foreign experience shows that online education use in combination with full-time course education gives an effective result. Different technologies of a mixed education are possible: $40 \%$ online education and $60 \%$ studying in class or $80 \%$ online study and $20 \%$ "face to face" lessons $[4,9]$. Such kind of education includes 
three main components - traditional interaction of an educational process, interactive interaction and self-education [10]. However, complete avoidance of contact between a teacher and students is not supposed.

Distance education would be effective only in case of several conditions:

1. Material base improvement, convenient educational platforms creation. They provide the opportunity to interact constantly.

2. Students' information competence level increase, the amount of tasks increase. They provide information technologies use.

3. The amount of students' independent work increase, directed toward information search, structuring and systematization.

4. Taking into account the recommendations of students concerning the content and form of material presentation during distant lessons organization.

Thus, distant technologies use is possible not only as a coercive measure, but also as a form of constant lessons organization. However, this form of education demands more detailed content consideration and the definite level of professional and psychological readiness not only among teachers, but among students.

\section{References}

1. Strategy of information society development in the Russian Federation during the period 2017-2030. URL: https://www.garant.ru/products/ipo/prime/doc/71570570/

2. A.S. Berberyan, Pre-Congress 9 World Congress for Psychotherapy "Children, Society and Future - the Planet of psychotherapy" (Moscow, June, 24-29)

3. A.S. Kuznetsova, Z.M. Kuznetsova, Russian Journal of Physical Education and Sport, 14(4), 5-7 (2019) L.M. Andryukhina, N.O. Sadovnikova, S.N. Utkina, A.M. Mirzaahmedov, The Education and Science Journal, 3(22), 122 (2020)

4. $\quad$ N.R. Bukeikhanov, S.I. Gvozdkova, E.V. Butrimova, Russian regions: looking into the future. 7(2), 63 (2020)

5. J.M. Roschina, S.J. Roshcin, V.N. Rudakov, Educational Studies Moscow, 1, 174-199 (2018)

6. F.M. Al-Madani, The Education and Science Journal, 5(22), 132-149 (2020).

7. A.M. Alinezi, The Education and Science Journal, 4(22), 89-109 (2020)

8. C. Bonk, The handbook of blended learning: Global perspectives, local designs (URL: http:// curtbonk.com / toc_section_intros2.pdf)

9. M.P. Lapchik, Training of teachers in the conditions of education informatization (Publishing House BINOM, Moscow, 2013) 